\title{
Parameter Vertex Color Pada Animasi Procedural 3D Model Vegetasi Musaceae
}

\author{
Vertex Color Parameter On Procedural Animation 3D Model Of Vegetation Musaceae
}

\author{
I Gede Ngurah Arya Indrayasa*1, M. Suyanto ${ }^{2}$, Hanif Al Fatta ${ }^{3}$ \\ ${ }^{1,2,3}$ Studi Magister Teknik Informatika, Program Pascasarjana STMIK Amikom Yogyakarta \\ Jl. Ring Road Utara Condong Catur Sleman Yogyakarta, Telp (0274) 884208 \\ e-mail: *11 aryashinigami@gmail.com, ${ }^{2}$ yanto@amikom.ac.id, ${ }^{3}$ hanif.a@amikom.ac.id
}

\begin{abstract}
Abstrak
Penggunaan vegetasi untuk industri film, video game, simulasi, dan arsitektur visualisas merupakan faktor penting untuk menghasilkan adegan pemandangan alam lebih hidup. Penelitian ini bertujuan untuk mengetahui pengaruh dari vertex color terhadap efek angin pada animasi prosedural $3 \mathrm{~d}$ model vegetasi musaceae serta parameter vertex color yang tepat untuk menghasilkan animasi $3 \mathrm{~d}$ model vegetasi musaceae realistis. Hasil akhir yang di capai adalah meneliti apakah perubahan parameter vertex color dapat mempengaruhi bentuk animasi procedural $3 \mathrm{~d}$ vegetasi musaceae serta pengaruh dari vertex color terhadap efek angin pada animasi prosedural $3 \mathrm{~d}$ model vegetasi Musaceae. Berdasarkan pengamat dan perbandingan pada pengujian 5 sample vertex color diperoleh hasil bahwa perubahan parameter vertex color dapat mempengaruhi bentuk animasi procedural $3 \mathrm{~d}$ vegetasi musaceae serta di peroleh kesimpulan Sample No.5 merupakan parameter vertex color yang tepat untuk menghasilkan animasi $3 \mathrm{~d}$ model vegetasi Musaceae yang realistis.
\end{abstract}

Kata kunci-3D, Animasi Prosedural, Vegetation

\begin{abstract}
The use of vegetation for the film industry, video games, simulation, and visualisas architecture is an important factor to produce more vivid landscape scene. This study aims to determine the effect of the vertex color to the effects of wind on procedural animation $3 d$ models musaceae vegetation and vertex color appropriate parameter to generate animated $3 D$ models of vegetation musaceae realistic. The final result is achieved is to examine whether the vertex color change parameters can affect the shape of procedural animation $3 d$ musaceae vegetation and the influence of vertex color to the effects of wind on procedural animation $3 d$ models musaceae vegetation. Based on a comparison of the observer and 5 testing samples showed that the vertex color vertex color change parameters can affect the shape of procedural animation and $3 D$ vegetation musaceae obtained conclusion Sample \# 5 is a parameter appropriate vertex color to produce animated $3 d$ models musaceae realistic vegetation.
\end{abstract}

Keywords - 3D, Procedural Animation, Vegetation

\section{PENDAHULUAN}

Ada berbagai macam teknik untuk menghasilkan grafis dan animasi vegetasi yang realistis. Salah satunya adalah menggunakan teknik procedural animation. Animasi prosedural adalah sebuah pendekatan (cara) untuk membuat animasi. Ini bukan sebuah "corak/style" dari animasi, namun animasi yang dibuat dengan pendekatan prosedural yang mempunyai "style" tertentu.

Animasi prosedural adalah salah satu jenis animasi komputer yang digunakan untuk men-generate animasi real time untuk menghasilkan berbagai macam animasi secara otomatis daripada membuatnya menggunakan animasi tradisional secara manual. Ini dipakai untuk 
mensimulasikan particle systems (asap, api, air), kain dan pakaian, rigid body dynamics, rambut dan bulu, serta animasi karakter seperti ragdoll.

Penggunaan 3D model vegetasi yang terdiri dari tumbuhan dan pepohonan telah secara luas digunakan dalam penggambaran pemandangan/scene alam dalam industri film animasi, video game, simulasi, dan visualisasi arsitektur. Penggunaan vegetasi untuk industri ini juga merupakan faktor penting untuk menghasilkan scene pemandangan alam yang lebih hidup dan realistis dari segi tampilan grafis dan animasi.

Animasi prosedural pada vegetasi tumbuhan ini menggunakan metode Touch bending dan Detail bending . Touch bending adalah metode pengaturan untuk simulasi interaksi fisika antara player dan vegetasi pada ranting dan dedaunan yang akan menekuk atau melengkung ketika terjadi kontak tumbukan (collision). Detail bending pada vegetasi berfungsi untuk pergerakan animasi prosedural pada dedaunan, yang disebabkan oleh angin atau pengaturan[1] fisik yang lain di dalam scene. Jumlah angin yang mempengaruhi objek $3 \mathrm{D}$ vegetasi pada animasi procedural dikendalikan oleh vertex color. Vertex color atau color maps adalah metode untuk menyimpan informasi warna Merah, Hijau, Biru, dan Alpha (RGBA) pada setiap vertex di permukaan mesh atau polygon.[2]

Baiquni Abdilah [3] Pada penelitiannya membuat sebuah animasi Penerapan Procedural Animation Untuk 3d Model Vegetasi Pada Video Animasi Fly Through 3d Environment yang berjudul "Sacred Temple Of Deep Jungle" , pada penelitian nya dalam membuat animasi fly through baiquni menerapkan teknik Animation procedural untuk 3D environtmen vegetasi (Baiquni, 2015) ,di antaranya terdapat 3D model vegetasi musaceae. Namun dalam implementasi penelitian nya hanya menitikberatkan pada animasi fly through dan sedikit membahas mengenai vertex color dan pengaruhnya pada animasi prosedural khusunya pergerakan vegetasi yang di sebabkan oleh efek angin ,sehingga tidak ada tolak ukur atau parameter pada vegetasi animasi prosedural .

Penelitian ini meneliti pengaruh dari Vertex color terhadap efek angin pada animasi prosedural $3 \mathrm{~d}$ model vegetasi Musaceae. Hasil akhir yang peneliti capai adalah mengetahui pengaruh dari vertex color terhadap efek angin pada animasi prosedural $3 \mathrm{~d}$ model vegetasi Musaceae serta mengetahui parameter vertex color yang tepat untuk menghasilkan animasi $3 \mathrm{~d}$ model vegetasi Musaceae yang realistis.

Renaldas Zioma [1] menjelaskan Konsep dasar animasi prosedural pada vegetasi tumbuhan ini menggunakan sistem hirarki struktur sebuah pohon, yang terdiri dari batang utama, dahan, ranting, kemudian daun dengan root segment terletak di batang utama. Setiap segmen ini saling terkoneksi membentuk ikatan joint yang setiap segmennya dapat berotasi dengan titik tumpu pada setiap parent segment.

Habel, R [2] menjelaskan jumlah angin yang mempengaruhi objek 3D vegetasi pada animasi procedural dikendalikan oleh vertex color. Vertex color atau color maps adalah metode untuk menyimpan informasi warna Merah, Hijau, Biru, dan Alpha (RGBA) pada setiap vertex di permukaan mesh atau polygon.

Baiquni Abdilah [3] Pada penelitiannya membuat sebuah animasi Penerapan Procedural Animation Untuk 3d Model Vegetasi Pada Video Animasi Fly Through 3d Environment yang berjudul "Sacred Temple Of Deep Jungle" , pada penelitian nya dalam membuat animasi fly through baiquni menerapkan teknik Animation procedural untuk 3D environtmen vegetasi . Dalam implementasi penelitian nya hanya menitikberatkan pada animasi fly through .

Tiago Sousa [4] menjelaskan Animasi prosedural pada vegetasi tumbuhan ini menggunakan metode Touch bending .Touch bending adalah metode pengaturan untuk simulasi interaksi fisika antara player dan vegetasi pada ranting dan dedaunan yang akan menekuk atau melengkung ketika terjadi kontak tumbukan (collision).prosedur ini menggunakan setup berbasis bone (penulangan) .

Derzaph , Tina LM, and Howard J. Hamilton [5] , menyebutkan Vegetasi merupakan bagian penting dari penggambaran realistis pemandangan alam dalam environment virtual 3D. Untuk meningkatkan realisme animasi 3D model Vegetasi, efek dari angin pada gerakan dan 
pertumbuhan tanaman harus dimodelkan.

\section{METODE PENELITIAN}

Penelitian ini menggunakan metode experimental ressearch, postest only control design. Yaitu melakukan penelitian dengan memanipulasi setidaknya satu variabel untuk mengetahui ada perubahan atau tidak pada variabel tersebut, sebelum dan sesudah dimanipulasi .[6] Langkah - langkah yang akan dilakukan dalam experimental research:

a. Mengidentifikasi dan mendefinisikan masalah. Dalam hal ini adalah masalah-masalah yang terdapat pada pengaruh dari vertex color terhadap efek angin pada animasi prosedural $3 \mathrm{~d}$ model vegetasi Musaceae . serta mengetahui parameter vertex color yang tepat untuk menghasilkan animasi $3 \mathrm{~d}$ model vegetasi Musaceae secara realistis. Hal pertama yang dilakukan dengan cara mengamati struktur morfologi vegetsai musaceae dan mengamati pergerakan ketika terkena angin.

b. Memformulasikan hipotesis dan konsekuensinya. Dalam penelitian ini Hipotesis akan dibuat berdasarkan analisa penulis dari tinjuan pustaka. Hipotesis berupa landasan yang digunakan dalam pembuatan sample vertex color.

c. Membuat rencana penelitian

d. Melakukan eksperimen.

e. Mengolah data eksperimen, dan mengubahnya menjadi bentuk yang dapat digunakan atau dipahami.

f. Mengambil kesimpulan.

Analisa Data secara keseluruhan akan menggunakan metode deskriptif yang sifatnya analisis kuantitatif. Dalam bagian ini, analisa data yang didapat digunakan mendeskrpsikan beberapa hal, dengan urutan sebagai berikut.

a) Untuk membuat Sample vertex color penulis membuat hipotesis berdasarkan data yang di peroleh untuk membuat sample vertex color vegetasi musaceae. Hipotesis ini akan menjadi landasan dalam pembuatan sample vertex color yang nantinya akan di uji menggunakan metode animasi prosedural menggunakan efek angin.

b) Untuk mengetahui pendapat ahli dan praktisi 3D artist, sebagai analisa data kuantitatif, akan digunakan metode analisa tingkat kepuasan pelanggan. 10 senior 3D artist akan di perlihatkan hasil animasi 5 sample vertex color dan vídeo dokumentasi vegetasi musaceae. Kemudian ahli dan praktisi 3D artist di minta untuk membandingkan tiap animasi sample vertex color dan vídeo dokumentasi kemudian menilai tiap sample serta memberi pendapat kelemahan tiap sample.. Hasil dari penilaian skor dari tiap sample kemudian di total. Skor terbesar akan menunjukan sample animasi vertex color vegetasi musaceae terhadap efek angin mirip dengan video dokumentasi.

Dibawah ini adalah Bagan Tahap Penelitian : 


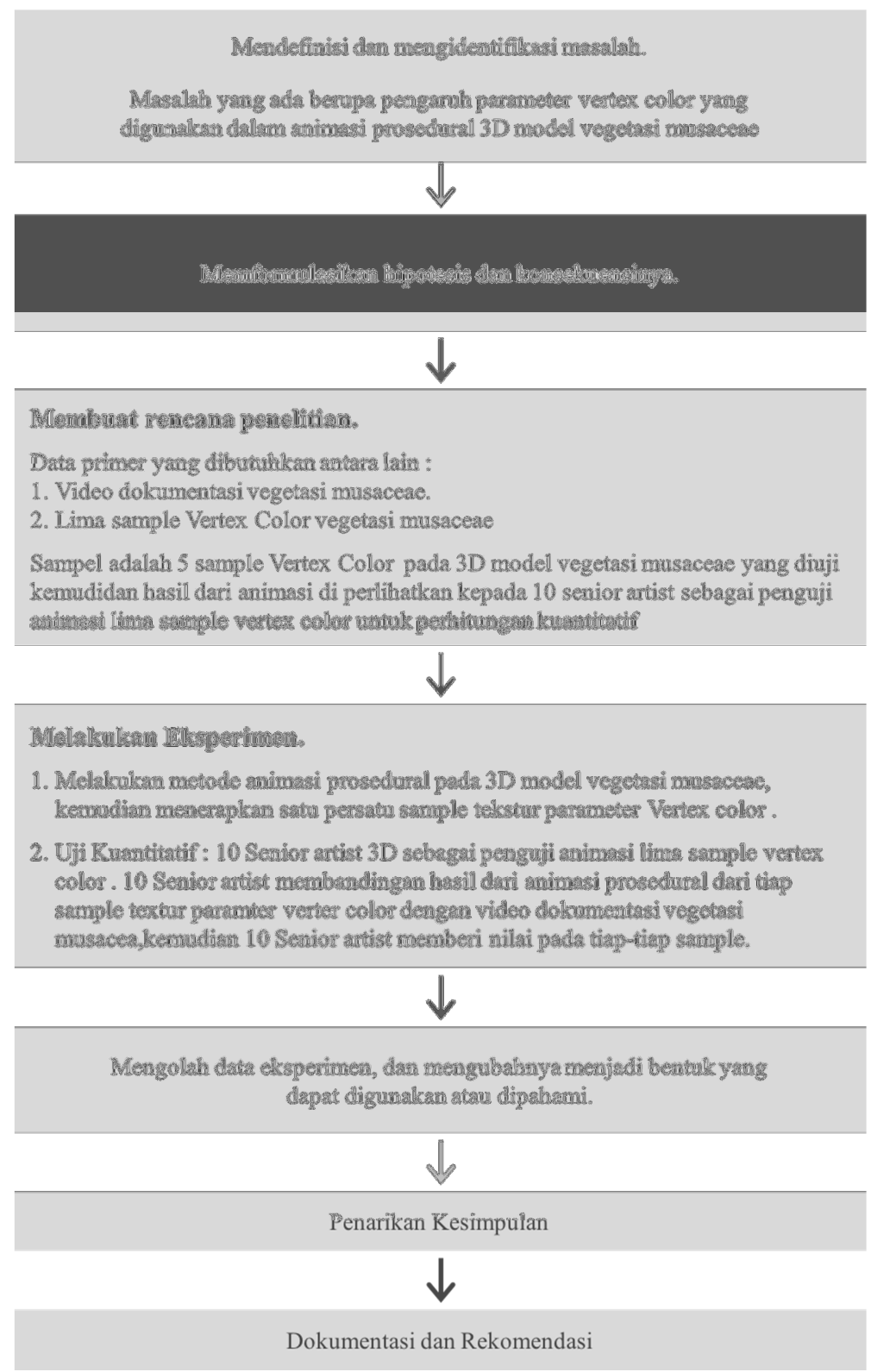

Gambar 1. Bagan Tahap Penelitian

\section{HASIL DAN PEMBAHASAN}

Dalam pembuatan Modeling aset vegetasi membutuhkan pengetahuan dan pemahaman lebih dalam mengenai morfologi tumbuhan musaceae (pisang) untuk menghasilkan aset vegetasi sesuai yang diharapkan. Tanaman Pisang (Musa paradisiaca) adalah tanaman berbentuk terna raksasa dengan batang semu yang permukaannya terlihat bekas pelepah daun. Tumbuhan ini tidak memiliki cabang, berbatang basah. Batang tumbuhan ini diselubungi oleh pelepah daunnya. Tumbuhan ini berasal dari daerah Asia Tenggara. [7]

Setelah mengetahui Morfologi Vegetasi langkah selanjutnya membuat workflow atau alur pembuatan asset $3 \mathrm{~d}$ vegetasi. Dibawah ini adalah workflow pembuatan aset vegetasi: 


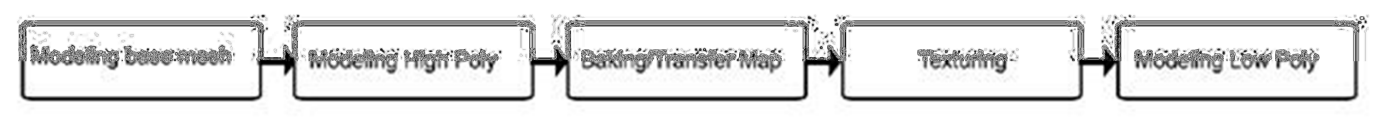

Gambar 2. Alur Pembuatan Aset Vegetasi

Tahap selanjutnya adalah Texturing Proses ini adalah proses pembuatan dan pemberian warna material (texture).tahap baking/transfer map menggunakan tool Transfer Maps di Maya sehingga bisa didapatkan tekstur Diffuse, Normal, Opacity,. Dibawah ini adalah tampilan tool Transfer Maps dan tekstur yang di dapatkan dari proses Transfer Maps.
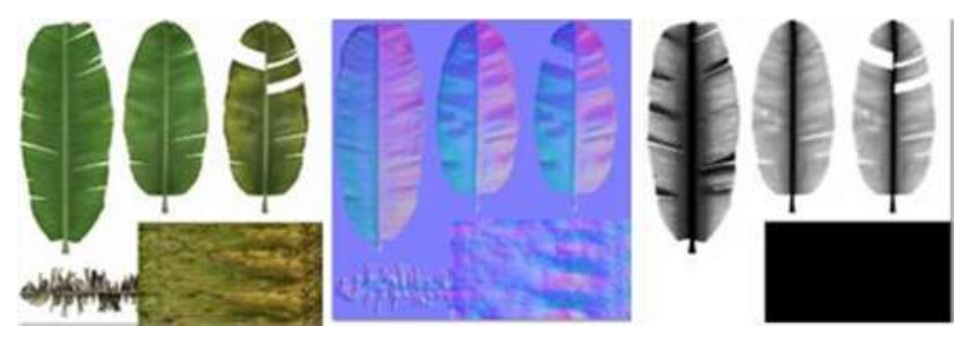

Gambar 3. Tekstur Diffuse, Normal, Opacity

Jumlah angin yang mempengaruhi objek 3D vegetasi pada animasi procedural dikendalikan oleh vertex color. Vertex color atau color maps adalah metode untuk menyimpan informasi warna Merah, Hijau, Biru, dan Alpha (RGBA) pada setiap vertex di permukaan mesh atau polygon. Dalam pembutan Sample vertex color penulis menggunakan refernsi pola Linier gradient dan Radial Gradient. Dalan penelitiannya Habel, R [2], menejelaskan representasi warna vertex color ( RGB ):

Red (Merah) : Warna merah menggerakkan vertex secara acak dan cepat,

Green (Hijau) : Warna hijau mengerakkan vertex 2 kali lebih pelan dari warna merah

Blue (Biru) : Warna biru menggerakan vertex 3 kali lebih pelan dari warna hijau

Berdasarkan penjelasan literature dan data yang diperoleh mengenai vegetasi musaceae peneliti mengambil hipotesis dalam pembuatan sample vertex color vegetasi musaceae dengan parameter sebagai berikut:

Red (Merah) : Warna merah menggerakkan vertex secara acak dan cepat ( dalam vegetasi musaceae digunakan untuk titik dalam menggerakan Helian daun dan Tangkai daun )

Green (Hijau) : Warna hijau mengerakkan vertex 2 kali lebih pelan dari warna merah( dalam vegetasi musaceae digunakan untuk titik dalam menggerakan Helian daun dan Tangkai daun )

Blue (Biru) : Warna biru menggerakan vertex 3 kali lebih pelan dari warna hijau ( dalam vegetasi musaceae digunakan untuk titik tumpu dalam menggerakan Tangkai daun,pelapah daun dan batang semu )

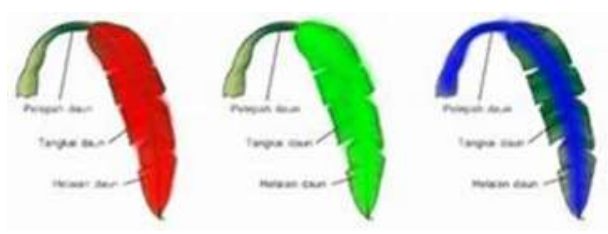

Gambar 4. Hipotesis Pola vertex color pada vegetasi musaceae

Dari Hipotesis diatas kemudian diperoleh pola dasar dalam pembuatan sample vertex color dengan urutan warna Blue(biru) - Green(hijau) - Red(merah) dalam pembuatan samplenya .peneliti menggunakan pola Linier Gradient, Radial Gradient dan gabungan kedua pola 
Gradient. Linier Gradient disebut juga axial gradient adalah gradasi warna yang menggunakan minimal 2 point (warna) garis lurus (line) .[8]
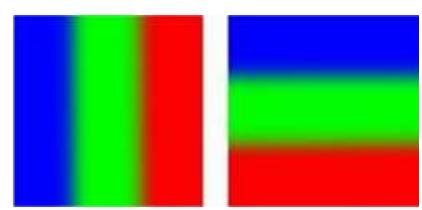

Gambar 5. Linier/Axial Gradient

Sedangkan Radial Gradient adalah gradasi warna yang memberntuk lingkaran yang memiliki warna satu di tepi dan yang lain ditengah .
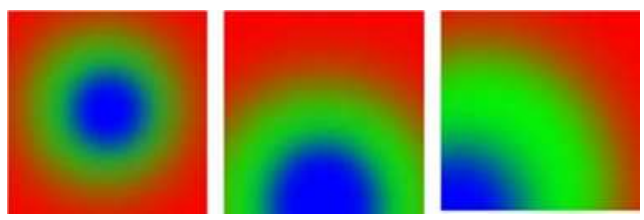

Gambar 6. Radial Gradient

Berdasarkan literature dan data yang diperoleh penulis membuat 5 sample menggunakan parameter RGB di atas. Berikut 5 sample vertex color yang di buat berdasarkan parameter :

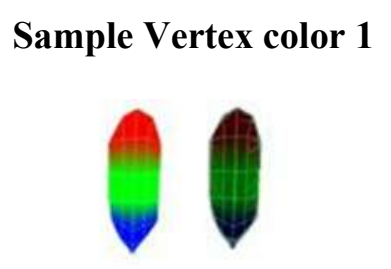

Gambar 7. Sample 1

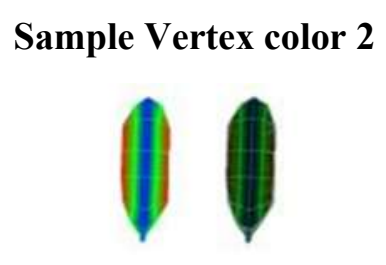

Gambar 8. Sample 2

\section{Sample Vertex color 3}

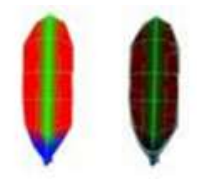

Gambar 9. Sample 3

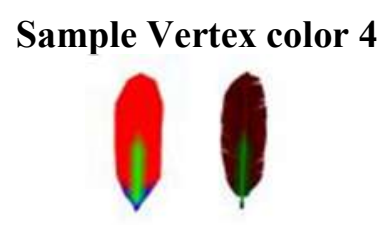

Gambar 10. Sample 4

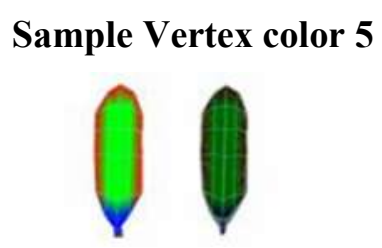

Gambar 11. Sample 5

Setelah Pembuatan sample berdasarkan paramter yang ada, langkah selanjutnya melakukan uji coba animasi procedural terhadap 5 sample vertex color. Uji coba animasi procedural dilakukan menggunakan software cry engine karena hasil bisa dilihat secara realtime. penelitian ini terdapat 4 parameter efek angin yang digunakan dalam yaitu, Bending branch amplitude, Bending edge amplitude, Detail bending frequency dan Wind Vector. Pada penelitian ini uji coba sample vertex color dilakukan menggunakan parameter angin normal dan parameter angin badai. Pengaturan parameter angin normal dan angin badai [3] menggunakan angka sebagai berikut : 


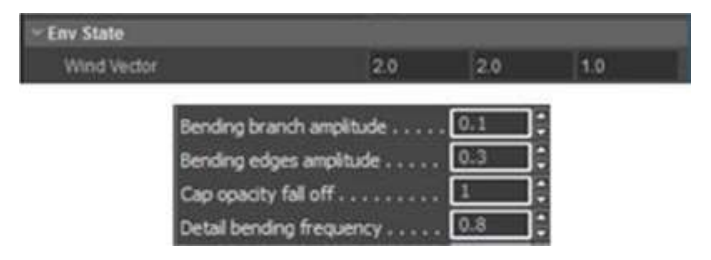

Gambar 12. Parameter angin normal

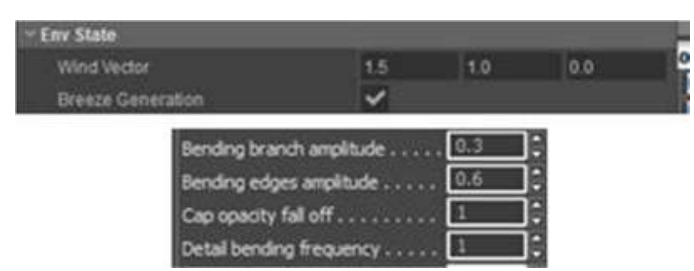

Gambar 13. Parameter angin badai

Pengujian yang selanjutnya dilakukan oleh peneliti adalah menguji kualitas hasil Sample Vertex Color Terhadap Efek Angin. Pengujian dilakukan dengan metode analisa kepuasan pelanggan. Yaitu dengan mewawancarai 10 senior artist 3D (yang minimal bekerja 2 tahun pada bidang 3D), untuk dimintai skor terkait hasil pengujian Vertex color terhadap efek angin pada animation procedural

10 senior 3D artist akan di perlihatkan hasil animasi 5 sample vertex color dan vídeo dokumentasi vegetasi musaceae. Kemudian ahli dan praktisi 3D artist di minta untuk membandingkan kemiripan gerak vegetasi musaceae pada efek angin tiap animasi sample vertex color dan vídeo dokumentasi kemudian menilai setiap sample serta memberi pendapat kelemahan tiap sample. Ahli dan praktisi diminta memberi skor 1-100 pada setiap hasil animasi . Hasil dari penilaian skor dari tiap sample kemudian di total. Skor terbesar akan menunjukan sample animasi vertex color vegetasi musaceae terhadap efek angin mirip dengan video dokumentasi.

Tabel 3. Hasil Pengujian pada 10 Senior 3D artist

\begin{tabular}{|c|c|c|c|c|}
\hline Sample 1 & Sample 2 & Sample 3 & Sample 4 & Sample 5 \\
\hline 60 & 60 & 60 & 70 & 80 \\
\hline 52 & 55 & 67 & 73 & 77 \\
\hline 61 & 62 & 70 & 74 & 78 \\
\hline 50 & 55 & 60 & 75 & 75 \\
\hline 60 & 65 & 55 & 68 & 70 \\
\hline 55 & 60 & 70 & 70 & 75 \\
\hline 45 & 50 & 65 & 65 & 70 \\
\hline 60 & 65 & 68 & 70 & 75 \\
\hline 50 & 60 & 70 & 70 & 70 \\
\hline 50 & 55 & 60 & 65 & $\mathbf{7 4 5}$ \\
\hline 543 & $\mathbf{5 8 7}$ & $\mathbf{6 4 5}$ & $\mathbf{7 0 0}$ & 75 \\
\hline
\end{tabular}


Dari data uji kualitas hasil sample vertex color pada efek angin yang dilakukan ahli dan praktisi 3d artist . Berdasarkan pengamatan dan perbandingan hasil animasi procedural vegetasi musaceae dengan video dokumentasi diperoleh hasil sebagai berikut:

Tabel 4. Analisis Hasil

\begin{tabular}{|c|c|c|}
\hline No & Hasil ujicoba sample & Keterangan \\
\hline 1 & & $\begin{array}{l}\text { Animasi procedural pada sample } 1 \\
\text { menggunakan angin normal dan angin } \\
\text { badai menunjukan pada bagian atas ( lihat } \\
\text { gambar sebelah kiri ) terjadi pelebaran } \\
\text { yang menyebabkan pergerakan tidak } \\
\text { seeimbang dan tidak realistis . }\end{array}$ \\
\hline 2 & & $\begin{array}{c}\text { Animasi procedural pada sample } 2 \\
\text { menggunakan angin normal dan angin } \\
\text { badai menunjukan pada bagian tengah pada } \\
\text { warna green (lihat gambar sebelah kiri) } \\
\text { terjadi penekukan yang menyebabkan } \\
\text { pergerakan patah pada bagian tengah dan } \\
\text { tidak realistis . }\end{array}$ \\
\hline 3 & & $\begin{array}{c}\text { Animasi procedural pada sample } 3 \\
\text { menggunakan angin normal dan angin } \\
\text { badai menunjukan pada bagian warna red } \\
\text { tepatnya bagian helian daun (lihat gambar } \\
\text { sebelah kiri) terjadi penekukan yang } \\
\text { menyebabkan pergerakan patah pada } \\
\text { bagian tengah dan tidak realistis . }\end{array}$ \\
\hline 4 & & $\begin{array}{c}\text { Animasi procedural pada sample } 4 \\
\text { menggunakan angin normal dan angin } \\
\text { badai menunjukan pada bagian tengah } \\
\text { warna green tepatnya pada tangkai daun } \\
\text { bawah (lihat gambar sebelah kiri) terjadi } \\
\text { penekukan yang menyebabkan pergerakan } \\
\text { patah pada bagian tengah dan tidak } \\
\text { realistis. }\end{array}$ \\
\hline
\end{tabular}




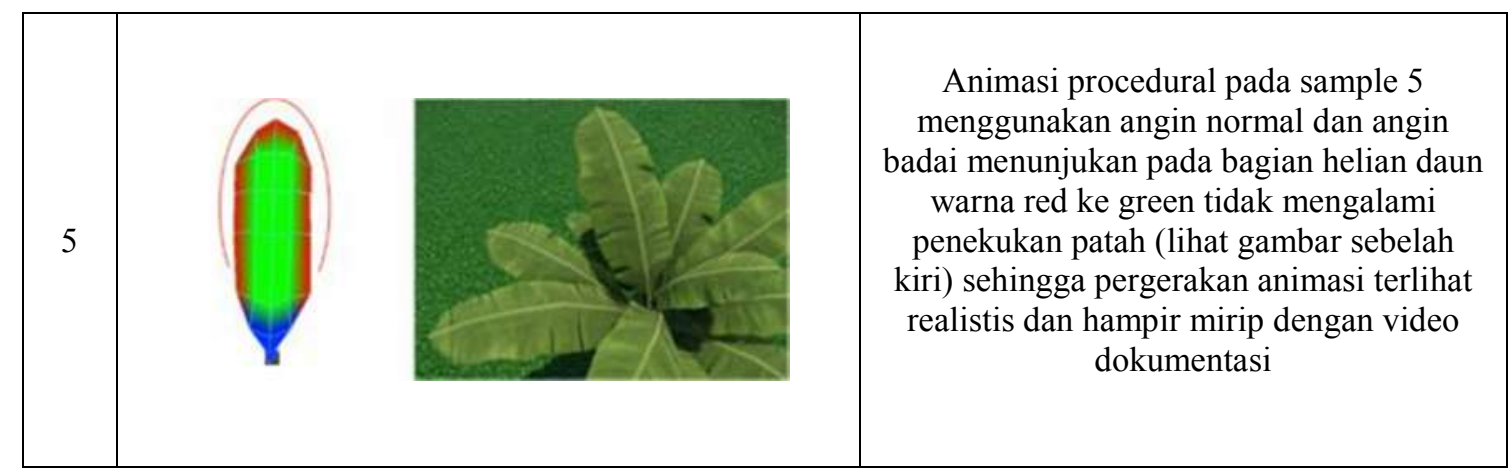

\section{KESIMPULAN}

Berdasarkan penelitian yang telah dilakukan, dapat diambil kesimpulan antara lain:

a) Verter color berpengaruh terhadap efek angin pada animasi prosedural $3 \mathrm{~d}$ model vegetasi musaceae

b) Perubahan parameter vertex color dapat mempengaruhi bentuk animasi procedural $3 \mathrm{~d}$ vegetasi musaceae. Hal ini dapat dilihat pada pengujian 5 sample vertec color, perubahan parameter verex color mempengaruhi gerak animasi vegetasi musaceae.

c) Pengujian terhadap 5 sample vertex color yang di uji oleh ahli dan praktisi 3D artis menyimpulkan sample vertex color no.5 mendekati mirip video dokumentasi .

d) Pengujian sample vertec color membuktikan hipotesis penulis dalam pembuatan parameter vertex color .

- Red (Merah) : Dalam vegetasi musaceae digunakan untuk titik dalam menggerakan Helian daun dan Tangkai daun

- Green (Hijau) : Dalam vegetasi musaceae digunakan untuk titik dalam menggerakan Helian daun dan Tangkai daun

- Blue (Biru) : Dalam vegetasi musaceae digunakan untuk titik tumpu dalam menggerakan Tangkai daun,pelapah daun dan batang semu

e) Penganimasian animasi procedural 3D model vegetasi musaceae menggunakan teknik detail bending yang memanfaatkan vertex color sangat memudahkan proses produksi, karena tumbuhan tidak perlu dianimasikan satu per satu.

\section{SARAN}

Berdasarkan hasil penelitan yang telah disimpulkan diatas, maka dalam upaya pengembangan dikemukakan saran sebagai berikut :

a) Penelitian ini meneliti bagaimana pengaruh verter color terhadap efek angin pada animasi prosedural $3 \mathrm{~d}$ model vegetasi musaceae .Diharapkan dengan adanya penelitian ini dapat menjadi acuaan penelitian lain untuk mengembangkan metoder animasi presedural lainnya serta dapat menjadi acuan dalam pengembangan penggunan vertex color .

b) Hasil paramter vertex color $3 \mathrm{~d}$ model vegetasi musaceae pada penelitian ini dapat digunakan sebagai acuan untuk dikembangkan pada implementasi $3 \mathrm{~d}$ model vegetasi lain. 


\section{DAFTAR PUSTAKA}

[1]Zioma Renaldas, 2009, GPU-Generated Procedural Wind Animations for Trees, GPU Gems 3, Addison-Wesley Professional, chapter 6.

[2]Habel, Ralf, 2010, Real-time rendering and animation of vegetation. Diss, Habel.

[3] Baiquni Abdillah, Dhani Ariatmanto, 2014, Analisis Dan Penerapan Procedural Animation Untuk 3d Model Vegetasi Pada Video Animasi Fly Through 3d Environment 'Sacred Temple Of Deep Jungle' Menggunakan Cryengine 3.5.8, Skripsi, Stmik Amikom Yogyakarta.

[4]Tiago Sousa, 2009, Vegetation Procedural Animation and Shading in Crysis, GPU Gems 3.

[5]Derzaph, Tina LM, and Howard J. Hamilton, 2013 ,Effects of wind on virtual plants in animation, International Journal of Computer Games Technology 2013: 3.

[6]Solso, R. L MacLin, M. K, O. H, 2005, Cognitive Psychologi. New York. Pearson

[7]Van Steenis, C.G.G.J., 2003, Flora, P.T. Pradya Paramita, Jakarta, hal 233-236.

[8]Asente, Paul; Carr, Nathan, 2013, Creating contour gradients using 3D bevels, Proceedings of the Symposium on Computational Aesthetics (CAE '13, Anaheim, California), New York, NY, USA: ACM 